\title{
O uso de objetos de aprendizagem em conceitos algébricos*
}

\author{
$\underline{\text { Elizandra K. Odorico }}^{* *} \quad$ Michele Maciel Sacramento** Andréa Cardoso \\ Instituto de Ciências Exatas, UNIFAL-MG \\ 37130-000, Alfenas, MG \\ E-mail: li.elizandra@gmail.com, michele_macielsacramento@hotmail.com, andreac74@uol.com.br
}

\begin{abstract}
RESUMO
O conteúdo de álgebra inicia-se nas séries finais do ensino fundamental, estendendo-se durante todo ensino médio. Contudo, tanto os estudantes do ensino médio quanto os de ensino superior vêm a álgebra como um conteúdo abstrato, sem relação com seu cotidiano, fato que gera uma deficiência em seu aprendizado. [1] sugere que a álgebra seja explorada por meio de jogos e representações matemáticas, de modo que permitam a dar significados a linguagem e as ideias da álgebra. Entretanto, os discentes possuem uma grande dificuldade neste conteúdo, especificamente na compreensão de incógnitas e na resolução das equações. Segundo [3] algumas dificuldades encontradas pelos alunos estão ligadas ao uso das letras para representar as incógnitas.

Para tentar minimizar tais dificuldades, é necessário buscar metodologias diferenciadas e ferramentas que auxiliem no processo de ensino-aprendizagem. Dentre elas, destacam-se o uso de objetos de aprendizagem (OA), como recurso didático. [2] constataram que os alunos conseguem descrever atividades com OA e entendem sua relação simbólica, ou seja, que uma letra pode representar qualquer número, compreendendo também a relação entre as letras e o número, comparando e conferindo resultados.

Deste modo, o objetivo deste trabalho é apresentar os procedimentos metodológicos adotados na aplicação de um OA denominado "Balança de Tomate" (RIVED-Rede Internacional Virtual de Educação. "Resolvendo equações através da balança". Disponível em: http://www.projetos.unijui.edu.br/matematica/fabrica_virtual/Antonio_miguel_e_Adilson_ Sella/index.html.) e os resultados da intervenção pedagógica. A atividade foi aplicada em uma turma do sexto ano do Ensino Fundamental de uma da instituição parceira do Programa Institucional de Bolsa à Iniciação a Docência (PIBID). A intervenção pedagógica foi desenvolvida no laboratório de ensino da Universidade Federal de Alfenas (UNIFAL). Observe na figura 1, durante duas aulas de cinquenta minutos, onde foi utilizada uma lousa interativa,
\end{abstract} para o desenvolvimento da atividade.

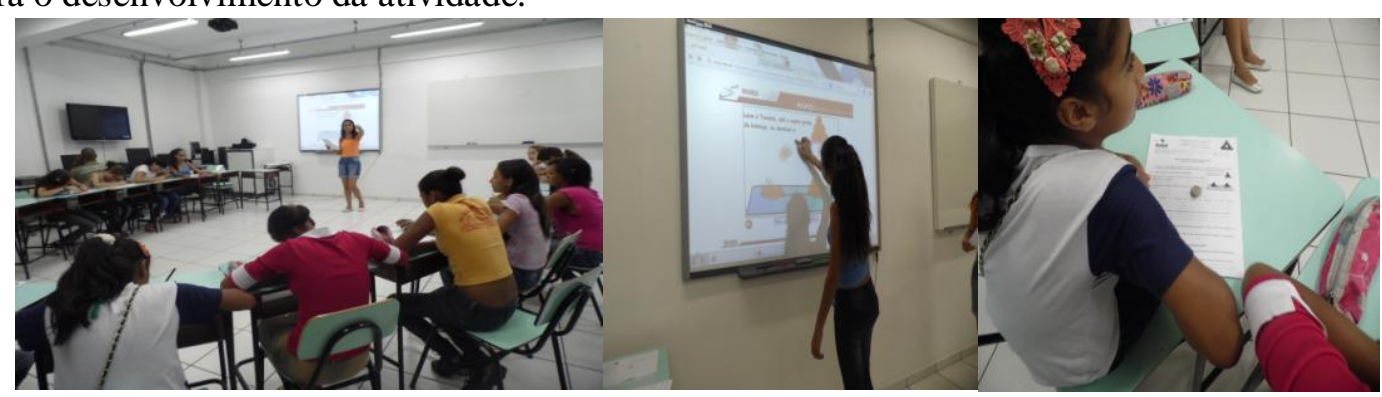

Figura1: A primeira imagem ilustra os alunos no laboratório de ensino com a bolsista de ID, a segunda uma aluna interagindo com a lousa digital e a última uma aluna com o caderno de acompanhamento.

Para um melhor desenvolvimento da intervenção, foram elaborados questionários investigativos e um caderno de acompanhamento, sendo que estes foram disponibilizados para cada um dos estudantes. Ainda, o caderno de acompanhamento era composto por sete atividades, sendo estas auxiliadas por setes fases do OA "Balança de Tomate". De modo geral,

\footnotetext{
* O presente trabalho foi realizado com apoio financeiro da Fundação de Amparo à Pesquisa do Estado de Minas Gerais (FAPEMIG) e do Programa Institucional de Bolsa de Iniciação à Docência (PIBID), da Coordenação de Aperfeiçoamento de Pessoal de Nível Superior (CAPES), Brasil.

** Bolsista de Iniciação à Docência PIBID/CAPES
} 
as fases iniciais eram mais fáceis, nas quais os alunos não tiveram dificuldades, sendo que estas fases envolviam ora a operações de adição e ora a subtração nas equações propostas. Já nas fases intermediárias, havia em algumas equações apenas a operação de multiplicação ou a de divisão, e neste momento os alunos apresentaram dúvidas para solucioná-las. E nas finais, que relacionavam todas as operações básicas, isto é, a operação de multiplicação com a adição e a divisão com a subtração, os alunos tiveram bastante dificuldade.

$\mathrm{Na}$ análise dos questionários investigativos notou-se que as maiores dificuldades apresentadas pelos estudantes foram no emprego das operações de multiplicação e divisão e na interpretação das atividades propostas. Além disso, os próprios alunos afirmam possuir um nível de conhecimento matemático médio ou ruim, sendo este fato evidenciado nos exercícios prévios aplicados na turma.

Durante a intervenção foi constatado que todos os alunos se interessaram com a sequência aplicada, pois envolvia o trabalho com OA e, principalmente, recursos tecnológicos. Assim, observou-se que quando o processo de resolução era realizado na lousa interativa, os estudantes buscavam retirar ou colocar tomates e sacolas sem nenhuma dificuldade. Entretanto, no momento em que eles deveriam realizar este procedimento no caderno de acompanhamento, evidenciou que alguns destes alunos se confundiam com as operações inversas, como por exemplo, não relacionando a retirada ou acréscimo com as operações de subtração e adição. Devido a isso, houve a necessidade de realçar outras equações apresentadas no OA, na qual, à medida que os próprios alunos manipulavam o objeto para igualar os pratos da balança, era representado o processo matemático que estava sendo realizado. Por exemplo, quando o aluno retirava três tomates da balança para igualá-la era representado, no quadro branco, a subtração de três quantidades.

Deste modo, a maioria dos alunos que não conseguiam resolver as equações no questionário investigativo inicial, compreendeu o processo mostrado durante a aplicação, com a adição ou retirada de membros de ambos os lados da igualdade, conseguindo resolver as equações sugeridas no caderno de acompanhamento. Assim, a atividade foi considerada adequada como introdução do estudo de equações polinomiais de primeiro grau, visto que apresenta situações que possibilitam a compreensão do conceito de equivalência e igualdade.

Desta forma, a utilização de recursos tecnológicos e objetos de aprendizagem disponíveis na web contribui no processo de ensino-aprendizagem, desde que seja adotada uma metodologia que favoreça a compreensão e construção dos conceitos fundamentais da matemática. Além disso, o uso destes recursos proporciona uma ligação entre conceitos matemáticos considerados abstratos com situações cotidianas, realçando a utilidade prática de alguns tópicos da matemática escolar.

Palavras-chave: Objetos de Aprendizagem, Álgebra, Ensino de Matemática.

\section{Referências}

[1] Brasil. Parâmetros curriculares nacionais: matemática. Brasília: MEC/SEF, 1998.

[2] R. S. Freire. J. A. Castro Filho, Desenvolvendo conceitos algébricos no ensino fundamental com o auxílio de um Objeto de aprendizagem. In: CONGRESSO DA SBC, XXVI, Campo Grande. Anais... 156-163, 2006.

[3] J. P. Ponte, Álgebra no currículo escolar. Educação e Matemática, n. 85, pp. 36-42, 2005. 